\title{
Vitamin D ameliorated endothelial cell damage induced by diabetes via regulation of IncRNA MEG3 in human umbilical vein endothelial cells
}

Hua Wei ${ }^{1}$, Qiongfang Zhang ${ }^{2}$, Jun $\mathrm{Li}^{1}$, Jing Yang ${ }^{3}$, Bin Huang ${ }^{1}$, Chun-chun Huang ${ }^{1}$, Ying-chuan Wang ${ }^{4}$, Jing-qian $\mathrm{Hu}^{4}, \mathrm{Xi} \mathrm{Wei}^{3}$

${ }^{1}$ Department of General Medicine, Affiliated Hospital of YouJiang Medical University
for Nationalities, Baise, Guangxi, China
2Department of General Medicine, The second NanNing people's hospital, NanNing
Guangxi, China
${ }^{3}$ Health Supervision Center, Affiliated Hospital of YouJiang Medical University for
Nationalities, Baise, Guangxi, China
${ }^{4}$ Graduate School, YouJiang Medical University for Nationalities, Baise, Guangxi, China

Submitted: 29 July 2020

Accepted: 1 October 2020

Arch Med Sci

DOI: https://doi.org/10.5114/aoms.2020.101248

Copyright @ 2020 Termedia \& Banach

\section{Abstract}

Introduction: The purpose of this study was to investigate long non-coding RNA (IncRNA) maternally expressed gene 3 (MEG3) effects in vitamin D (Vit. D) treatment in endothelial cell damage induced by diabetes.

Material and methods: We used human umbilical vein endothelial cells (HUVECS) as a research objective in our study and used high glucose in a diabetic cell model. We evaluated cell apoptosis by flow cytometry, inflammatory factors (IL-6, IL-1 $\beta$ and TNF- $\alpha$ ) concentrations by ELISA assay, relative gene and protein expression by RT-qPCR and WB assay, and NF-KB(p65) nuclear volume by cellular immunofluorescence.

Results: Compared with the NC (normal control) group, the cell apoptosis rate was significantly increased, inflammatory factor (IL-6, IL-1 $\beta$ and TNF- $\alpha$ ) concentrations were significantly up-regulated, IncRNA MEG3 gene expression was significantly depressed, Toll-like receptor 4 (TLR4), myeloid differentiation factor 88 (MyD88) and nuclear factor $\kappa B$ p65 (NF- $\kappa B(p 65)$ ) gene and protein expression levels were significantly increased and NF- $\kappa B(p 65)$ nuclear volume was significantly up-regulated $(p<0.001$, respectively). With Vit. D supplementation, compared with the Model group, $\checkmark$ it. $D$ improved endothelial cell damage induced by diabetes, while InCRNA MEG3 was significantly increased and the TLR4/MyD88/NF-kB(p65) pathway was significantly depressed dose-dependently (all $p<0.05$ ). With sh-MEG3 transfection, the Vit. D treatment effects were significantly reduced.

Conclusions: Vit. D improved endothelial cell damage induced by diabetes via IncRNA MEG3 up-regulation in vitro study.

Key words: vitamin D, endothelial cell damage, diabetic, IncRNA MEG3, TLR4, MyD88, NF- $\kappa B(p 65)$.

\section{Introduction}

Diabetic vasculopathy is one of the fatal chronic complications, including lesions in great vessels and capillaries of the heart, and peripheral vessels. Its pathogenesis includes multiple factors involved in different

\author{
Corresponding author: \\ Xi Wei \\ Health Supervision \\ Center \\ Affiliated Hospital \\ Youliang Medical \\ University for \\ Nationalities \\ Baise, Guangxi \\ China \\ E-mail: weixi0405@21cn.com
}


mechanisms, of which endothelial dysfunction is an early critical incident resulting in atherosclerosis [1], which is also a pathophysiological basis of diabetic vasculopathy. Therefore, improving or delaying endothelial dysfunction is an important approach to the prevention and treatment of diabetic vascular complications. Inflammation-mediated endothelial cell senescence, damage, dysfunction and oxidative stress are all involved in the formation of various cardiovascular diseases [2]. When vascular inflammation occurs, B lymphocytes, $\mathrm{T}$ lymphocytes and mononuclear-macrophages will be activated to produce a large amount of interleukin (IL)-6 and tumor necrosis factor (TNF)- $\alpha$, which are two important inflammatory factors closely linked to the inflammatory response. TNF- $\alpha$ can induce the formation of IL- 6 , and IL- 6 can induce vascular endothelial cell damage. El Habashy et al. [3] reported that TNF- $\alpha$ could regulate endothelial cell injury and remodeling via

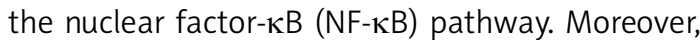
TNF- $\alpha$ could change endothelial cells' morphological and biological properties, while the endothelial cells at the junction would become longer and thinner in response to TNF- $\alpha$ [4]. In vitro cell studies have shown that TNF- $\alpha$ can promote endothelial cell apoptosis by regulating NF- $\mathrm{KB}$ and phosphatidylinositol-3-kinase pathways [5].

Al-Rasheed et al. [6] found that vitamin D (Vit. D) could reduce the expression of TNF- $\alpha$ by inhibiting the NF- $\mathrm{BB} / \mathrm{p} 65$ pathway, thus playing a crucial role in preventing or reducing cardiac hypertrophy and cardiovascular diseases, but further research is still needed for other pathways conducive to supporting a healthy heart. According to the research results of Sahar [7], Vit. D could significantly down-regulate the myocardial poly ADP-ribose polymerase, cyclooxygenase-2, TNF- $\alpha$, IL-6, caspase-3, Bax and p53, and reduce the infiltration of inflammatory cells in the myocardium, so as to protect cardiomyocytes and vascular endothelial cells. The myocardial cells of diabetic rats could be protected by improving hyperglycemia, dyslipidemia, an unbalanced REDOX process, inflammatory response and apoptosis, and the probability of acute myocardial infarction could be reduced. Nevertheless, the role and related mechanism of Vit. D in vascular endothelial injury caused by diabetes are still unclear.

RNA is not merely the messenger of information communication between proteins and DNA, and the essence of transcription is to generate all information of the eukaryotic genome into abundant non-coding RNA, which shows complex overlapping models of expression and regulation [8-10]. It has been found that IncRNA is closely related to the occurrence of many tumors, such as lung cancer [11], gastric cancer [12], etc. More- over, IncRNA shows an obvious correlation with the occurrence of immune system diseases [13], and the expression of various IncRNA has complex changes in the occurrence of pancreatic islet cell injury and diabetes $[13,14]$. Also, a previous study found that IncRNA MEG3 plays an important role in glucose-induced endothelial cell dysfunction [15]. There is no specific report about the role of LncRNA in diabetic vascular endothelial injury.

Diabetic vascular endothelial damage was simulated by using high glucose induced human umbilical vein endothelial cells (HUVECs). First, intervention was performed with Vit. D of different concentrations and the changes of related IncRNA and signaling pathways were analyzed, and then in vitro cell research was conducted to investigate the role of IncRNA MEG3 in Vit. D improving the vascular endothelial injury caused by high glucose.

\section{Material and methods}

\section{Experimental materials}

HUVECs were purchased from ScienCell, USA; DMEM low-sugar medium was purchased from Gibco, Batch No.: 1139385; ECM (containing ECGS, fetal bovine serum, penicillin, streptomycin solution) was purchased from ScienCell, Batch No.: 20285; Fetal bovine serum was purchased from PAN-Biotech, German, Batch No.: P130912; D(+)glucose was purchased from Sigma, Batch No.: WXBBll63V; Trypsin was purchased from Amresco, Batch No.: 2533C173; TNF- $\alpha$, IL-1 $\beta$ and IL-6 ELISA kits and shRNA-NC (shRNA-negative control) and sh-MEG3 were purchased from KeyGen BioTech (Nanjing, China).

A $\mathrm{CO}_{2}$ incubator (HF240, Heal Force); Clean bench (SW-CJ-2FD, Suzhou Antai Airtech Co., Ltd.); Inverted microscope (CX31, Olympus, Japan); UItrapure water machine (Milli Q, Millipore, USA); and ELIASA (Sunrise, Tecan, Switzerland) were used.

\section{Cell culture}

HUVECs were inoculated in a 6-well-plate at $1 \times 10^{4} /$ well and cultured in the low glucose (5.5 $\mathrm{mmol} / \mathrm{l}$ glucose) DMEM medium. The cells were placed in an incubator containing $5 \% \mathrm{CO}_{2}$ at $37^{\circ} \mathrm{C}$ and saturated humidity for routine culture, and the cells were subcultured after $70 \%$ to $80 \%$ fusion.

\section{Experimental grouping}

The whole experiment was divided into two parts: part I: NC group (normal glucose concentration, $5.5 \mathrm{mmol} / \mathrm{l}$ ); high glucose model group (33 mmol/l) [16]; Vit. D intervention group (intervention with $1 \mu \mathrm{g} / \mathrm{l}, 2 \mu \mathrm{g} / \mathrm{l}$, and $10 \mu \mathrm{g} / \mathrm{l}$ Vit. D (Sigma, USA)). Part II: NC group; model group; 
shRNA-N group (treated with high glucose after transfection with shRNA-NC); Vit. D group (high-glucose treatment and $10 \mu \mathrm{g} / \mathrm{l}$ Vit. D intervention); Vit. D + sh-MEG3 (high-glucose treatment and $10 \mu \mathrm{g} / \mathrm{l}$ Vit. D intervention after transfection with shRNA-MEG3).

Cell transfection involved adding HUVECs to a 12 -well plate at $1 \times 10^{4}$ /well, using DMEM medium with $5.5 \mathrm{mmol}$ glucose/l (normoglycemic medium) to culture, when the cell fusion rate was $30-50 \%$, adding $100 \mathrm{nmol} / \mathrm{l}$ shRNA-NC or sh-MEG3 and $5 \mu$ l of Lipofectamine into a 12-well plate to transfect, and continuing to culture for $48 \mathrm{~h}$ in DMEM medium with $5.5 \mathrm{mmol}$ glucose/l (normoglycemic medium). Then the next experiment was carried out.

Vit. D treatment methods: except the NC group, the Model, shRNA-NC, different Vit. D treated groups and Vit. D + sh-MEG3 group were cultured with high glucose medium, and the Vit. D treated group and Vit. D + sh-MEG3 group were treated with Vit. D for $48 \mathrm{~h}$. NC groups were treated with DMEM medium with $5.5 \mathrm{mmol}$ glucose/l (normoglycemic medium)h.

\section{RT-qPCR assay}

After the cells were given corresponding treatment, Trizol was used to extract total RNA and perform reverse transcription reaction in two steps according to the instructions of the reverse transcription kit: Step 1. Ice cooling of RNA immediately after $5 \mathrm{~min}$ at $65^{\circ} \mathrm{C}$; step 2. composition of reaction solution: $0.5 \mu \mathrm{l}$ RT Enzyme Mix, $0.5 \mu \mathrm{l}$ Primer Mix, $2 \mu \mathrm{l} 5 \times$ RT Buffer, $6 \mu$ l Nuclease-free Water, $1 \mu$ l RNA. Reaction conditions: $37^{\circ} \mathrm{C}, 15 \mathrm{~min}$ reverse transcription reaction to $98^{\circ} \mathrm{C}, 5 \mathrm{~min}$ enzyme inactivation reaction; real-time fluorescence quantitative PCR was conducted (primer design and synthesis were completed by Shanghai Invitrogen Biology Co., Ltd., Table I for details).

\section{Flow cytometry}

The cells in each group were collected after corresponding treatment for $24 \mathrm{~h}$, and then suspend- ed in $500 \mu \mathrm{l}$ of binding buffer, and PI and Annexin V-FITC dye solution were added. The apoptosis changes were detected by flow cytometry.

\section{Elisa assay}

The supernatant of cell culture medium in each group was collected, and the levels of TNF- $\alpha$, IL-6 and IL-1 $\beta$ were detected by ELISA according to the kit instructions (Sigma, USA).

\section{Western blotting (WB)}

Protein decomposition and extraction of the cells in each group were performed on the ice, and the loading buffer was added, and the protein was boiled at $100^{\circ} \mathrm{C}$ for 10 min for degeneration after the protein concentration was determined by BCA kit; the proteins were loaded at $30 \mu \mathrm{g} /$ well, separated with $10 \%$ (volume fraction) SDS-polyacrylamide gel electrophoresis (SDS-PAGE), transferred to polyvinylidene fluoride (PVDF) membrane, and covered with $5 \%$ skim milk for $2 \mathrm{~h}$, and then the membranes were washed with TBST for 5 min 4 times, and cut according to the different target protein molecule mass needed and the molecular mass indicated by the marker. The primary antibodies were incubated in the incubation box at $4^{\circ} \mathrm{C}$ overnight: GAPDH, TLR4, MyD88 and NF-кB(p65) (Abcam, UK), and the membranes were washed with TBST for $5 \mathrm{~min}$ four times on the next day; the sheep anti-rabbit secondary antibodies were incubated at room temperature for $1 \mathrm{~h}$, and the membranes were washed with TBST for 5 min 4 times. The ECL luminescent agent was added, the exposure imaging was carried out using the chemiluminescence imaging system, and the gray value of the strip was measured by Image I software. Semi-quantitative analysis of experimental groups was conducted to compare the relative expression level of each protein.

\section{Immunofluorescence staining of cells}

Cells were fixed with $4 \%$ polyformic acid for 60 min and washed with PBS for 3 times. Rabbit NF- $\mathrm{B}(\mathrm{p} 65)$ monoclonal antibody $(1: 100)$ was

Table I. Primer sequences

\begin{tabular}{|c|c|}
\hline Gene name & Primer sequence \\
\hline \multirow[t]{2}{*}{ IncRNA MEG3 } & F: 5'-GCUUCCCUUCUAUUCUGAAUCCUUU-3' \\
\hline & R: 5'-AAAGGAUUCAGAAUAGAAACCAAGC-3' \\
\hline \multirow[t]{2}{*}{ TLR4 } & F:5'-GGCATGATGTTGATTCTCGTTG-3' \\
\hline & R:5'-AGCATTCTGGTCCGACTGC-3' \\
\hline \multirow[t]{2}{*}{ MyD88 } & F:5'-CGAGAGCTGGAGCAAACGGAGTTCAAG-3' \\
\hline & R:5'-GCTGGCTAGTGATGGACCACACGCA-3' \\
\hline \multirow[t]{2}{*}{$N F-\kappa B(p 65)$} & F:5'-CTGAAGGACCGCGATACGTCT-3' \\
\hline & R:5'-GAGAAGTGGATCTGCCGAAT-3' \\
\hline
\end{tabular}


added directly after blocking with $5 \%$ normal goat serum for $30 \mathrm{~min}$ and incubated at room temperature for 90 min. After washing with PBS 3 times, FITC-labeled goat anti-rabbit fluorescence secondary antibody (1:100) was added and incubated in a dark place at room temperature for $60 \mathrm{~min}$. After washing with PBS 3 times, DAPI labeled nucleus was added, and incubated in a dark place at room temperature for $10 \mathrm{~min}$. After washing with PBS 3 times, the amount of green fluorescence in the nucleus was observed under a fluorescence microscope. The DAPI labeled nuclei were blue under fluorescence microscopy.

\section{Statistical analysis}

SPSS 20.0 statistical software package was used for data processing. The measurement data were expressed as mean \pm standard deviation (mean $\pm \mathrm{SD}$ ), the comparison between the two groups was completed with $t$-test, one-way ANOVA and $\chi^{2}$ analysis, and the enumeration data were expressed by the rate. $P<0.05$ indicated a statistically significant difference.

\section{Results}

Vit. D depressed apoptosis and downregulated cytokine concentration

Figure $1 \mathrm{~A}$ shows that the cell apoptosis rate in the high-glucose Model group was significantly increased $(p<0.001)$ compared with the NC group. After intervention with different concentrations of Vit. D, the apoptosis rate of the Vit. D group was significantly inhibited compared with the Model group (all $p<0.05$ ); moreover, there was a significant dose-effect relationship among different Vit. D groups (all $p<0.05$ ). The ELISA results showed that the concentrations of TNF- $\alpha, \mathrm{IL}-1 \beta$ and IL- 6 in the Model group were significantly increased compared with the NC group (all $p<0.001$, Figure $1 \mathrm{~B})$. After Vit. D intervention, the concentrations of TNF- $\alpha$, IL- $1 \beta$ and IL- 6 in the Vit. D intervention groups were significantly reduced compared with the Model group (all $p<0.05$, Figure $1 \mathrm{~B}$ ), and there were significant differences among different vit. D groups (all $p<0.05$ ).

\section{Effects of Vit. D on expression of related genes (IncRNA MEG3, TLR4, MyD88 and NF- $\mathrm{KB}(\mathrm{p} 65))$ and proteins (TLR4, MyD88 and NF- $\mathrm{KB}(\mathrm{p} 65))$}

By RT-qPCR, the expression of the IncRNA MEG3 gene was significantly reduced, and the expression levels of TLR4, MyD88 and NF- $\mathrm{KB}(\mathrm{p} 65)$ genes were significantly increased in the Model group compared with the NC group (all $p<0.001$, Figure $2 \mathrm{~A}$ ). After intervention with Vit. $\mathrm{D}$ of differ- ent concentrations, the expression of the IncRNA MEG3 gene in the Vit. D intervention group was significantly increased, and the expression levels of TLR4, MyD88 and NF-kB(p65) genes were significantly decreased compared with the Model group (all $p<0.05$, Figure $2 \mathrm{~A}$ ). Moreover, there was a significant dose-effect relationship among different Vit. $D$ groups in the expression of IncRNA MEG3, TLR4, MyD88 and NF- $\mathrm{B}(\mathrm{p} 65)$ genes (all $p<0.05$, Figure $2 A)$. WB detection showed that the expression levels of TLR4, MyD88 and NF- $\kappa B(p 65)$ in the Model group were significantly increased compared with the NC group (all $p<0.001$, Figure 2 B). After intervention with Vit. D of different concentrations, the expression levels of TLR4, MyD88 and NF- $\kappa B(p 65)$ proteins were significantly reduced compared with the Model group (all $p<0.05$, Figure $2 \mathrm{~B}$ ).

\section{Effects of Vit. D on NF- $\mathrm{KB}(\mathrm{p} 65)$ nuclear volume}

According to the cell immunofluorescence detection results, NF- $\mathrm{KB}(\mathrm{p} 65)$ nuclear volume of the Model group was significantly increased compared with the NC group (all $p<0.001$, Figure 3 ). After intervention with different concentrations of Vit. D, the amount of nuclear import of $\mathrm{NF}-\kappa \mathrm{B}(\mathrm{p} 65)$ protein in Vit. D group was significantly inhibited compared with the Model group (all $p<0.05$, Figure 3); moreover, there was a significant difference in the amount of nuclear import of NF- $\mathrm{KB}(\mathrm{p} 65)$ among different Vit. D groups (all $p<0.05$, Figure 3 ).

\section{Vit. D improved high glucose-induced vascular endothelial injury via IncRNA MEG3}

Flow cytometry results showed that the apoptosis rates in the Model group and shRNA-NC group were significantly increased $(p<0.001$, respectively) compared with the NC group, and the apoptosis rate in the Vit. $D$ group was significantly inhibited (all $p<0.001$, Figure 4 A) compared with the Model group. After transfection with the IncRNA MEG3 inhibitor sh-MEG3, the apoptosis rate in the Vit. D + sh-MEG3 group was significantly higher than that in the Vit. D group ( $p<0.001$, Figure 4 A). The ELISA results showed that the concentrations of TNF- $\alpha$, IL-1 $\beta$ and IL- 6 in the Model group and shRNA-NC group were significantly higher than those in the NC group (all $p<0.001$, Figure $4 \mathrm{~B}$ ); the concentration levels of TNF- $\alpha$, IL- $1 \beta$ and IL- 6 in the Vit. $D$ group were significantly reduced compared with the Model group (all $p<0.001$, Figure $4 \mathrm{~B}$ ); after transfection with the IncRNA MEG3 inhibitor sh-MEG3, the concentrations of TNF- $\alpha, I L-1 \beta$ and IL-6 in the Vit. D + sh-MEG3 group were signifi- 
A
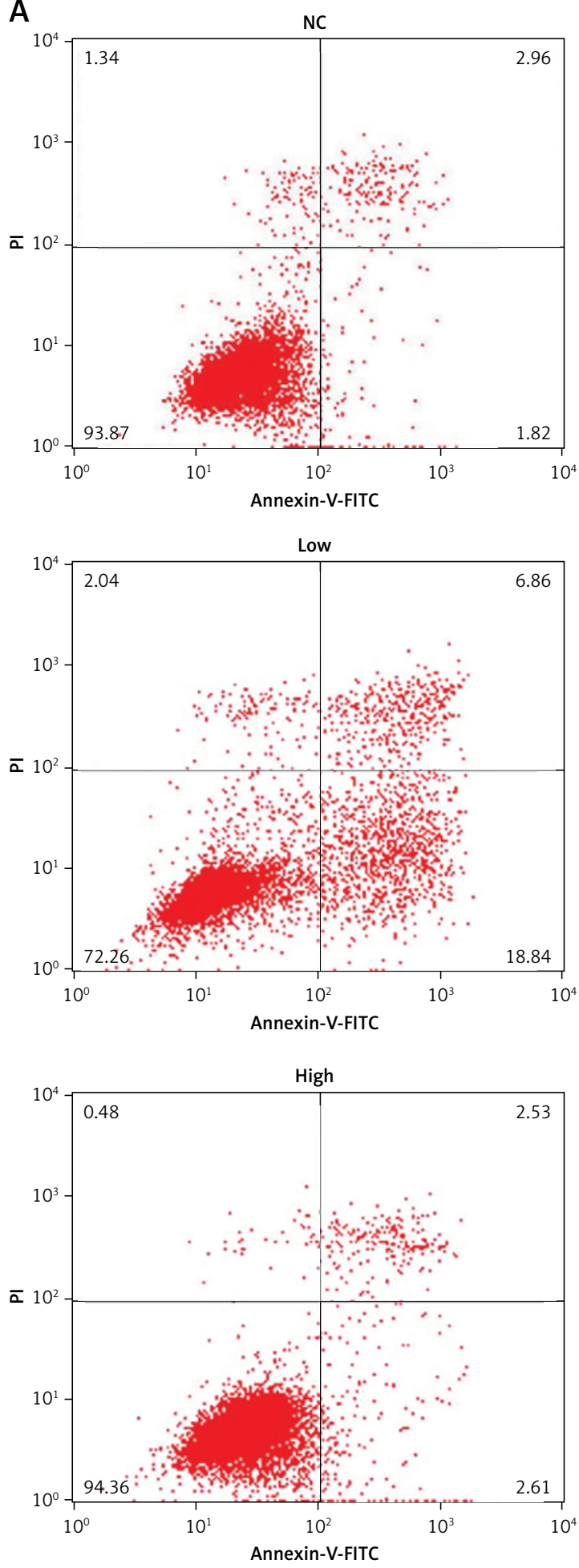
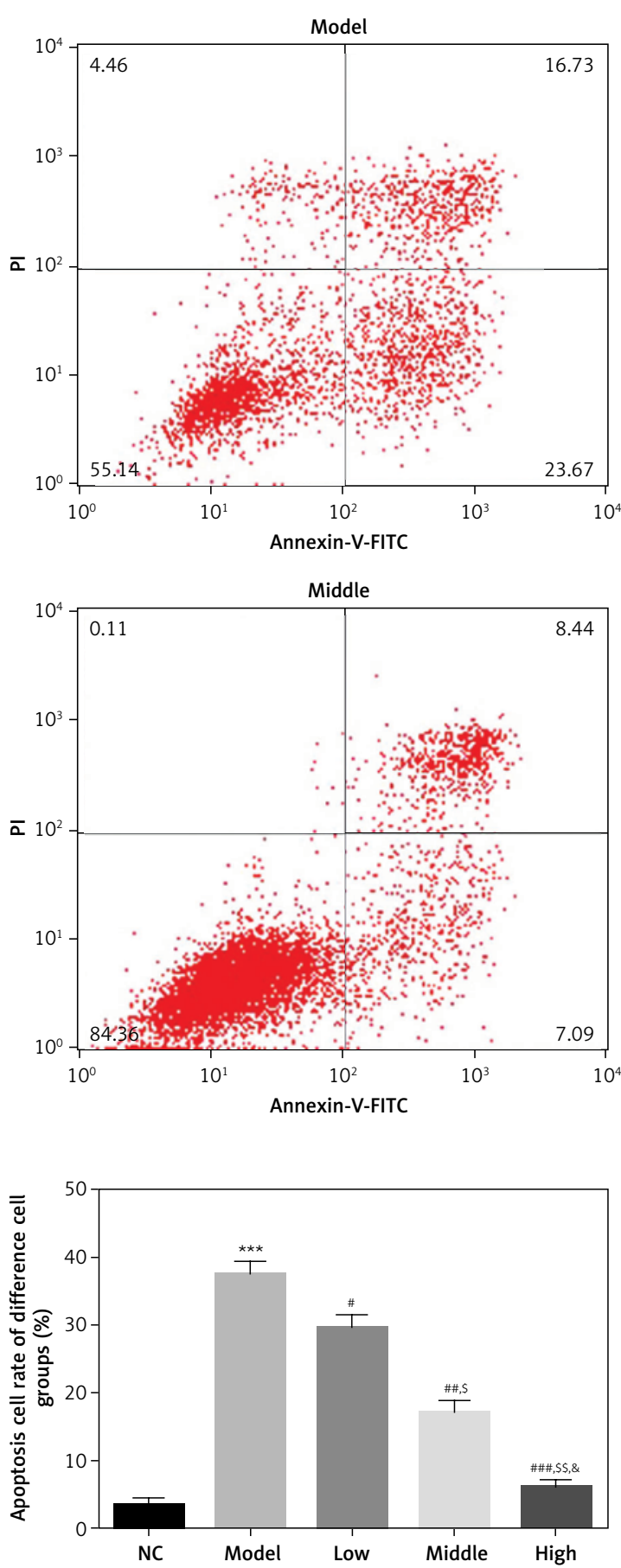

Figure 1. Effects of Vit. D on apoptosis and cytokine concentration. A - Apoptosis rate of different groups

NC - HUVECS treated with normal culture medium with normal glucose concentration, Model - HUVECs treated with high glucose, Low - HUVECs treated with high glucose and low-dose Vit. D, Middle - HUVECs treated with high glucose and middledose Vit. D, High - HUVECS treated with high glucose and high-dose Vit. D. ${ }^{* * *} P<0.001$, compared with NC group; ${ }^{\#} p<0.05$, ${ }^{\# \#} p<0.01,{ }^{\# \#} p<0.001$, compared with Model group; ${ }^{s} p<0.05,{ }^{s s} p<0.01$, compared with Low group; ${ }^{*} p<0.05$, compared with Middle group. 
B
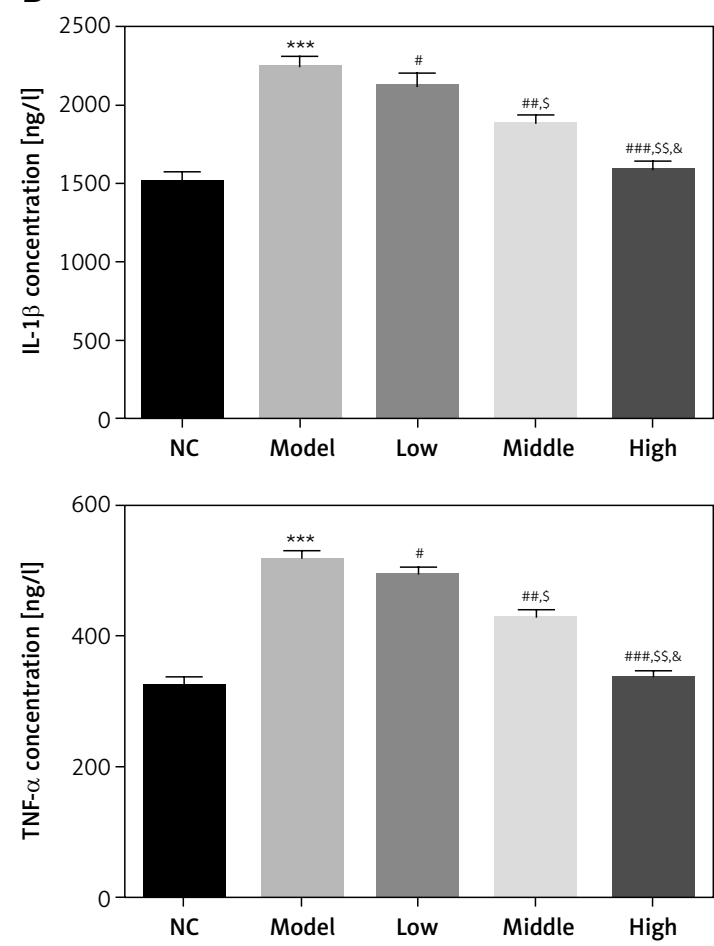

cantly higher than those in the Vit. D group (all $p<0.001$, Figure 4 B).

\section{Effects of IncRNA MEG3 knockdown on} expression of related genes (IncRNA MEG3, TLR4, MyD88 and NF- $\mathrm{KB}(\mathrm{p} 65))$ and proteins (TLR4, MyD88 and NF-kB(p65))

According to RT-qPCR results, the expression levels of IncRNA MEG3 genes in the Model group and shRNA-NC group were significantly decreased compared with the NC group, while the expression levels of TLR4, MyD88 and NF-kB(p65) were significantly increased (all $p<0.001$, Figure $5 \mathrm{~A}$ ). After Vit. D intervention, the expression level of the IncRNA MEG3 gene in the Vit. D group significantly increased compared with the Model group, while those of TLR4, MyD88 and NF- $\kappa B(p 65)$ were significantly decreased (all $p<0.001$, Figure $5 \mathrm{~A}$ ); after transfection with the IncRNA MEG3 inhibitor sh-MEG3, the expression level of MEG3 in the Vit. D + sh-MEG3 group was significantly reduced compared with that in the Vit. D group, while the expression levels of TLR4, MyD88 and NF- $\mathrm{KB}(\mathrm{p} 65)$ were significantly increased (all $p<0.001$, Figure $5 \mathrm{~A}$ ). The results of WB detection showed that the expression levels of TLR4, MyD88 and NF$\kappa \mathrm{B}(\mathrm{p} 65)$ in the Model group and shRNA-NC were significantly increased compared with the NC group (all $p<0.001$, Figure $5 \mathrm{~B}$ ); after intervention with Vit. D, the expression levels of TLR4, MyD88 and NF- $\kappa B(p 65)$ in the Vit. $D$ group were signifi-

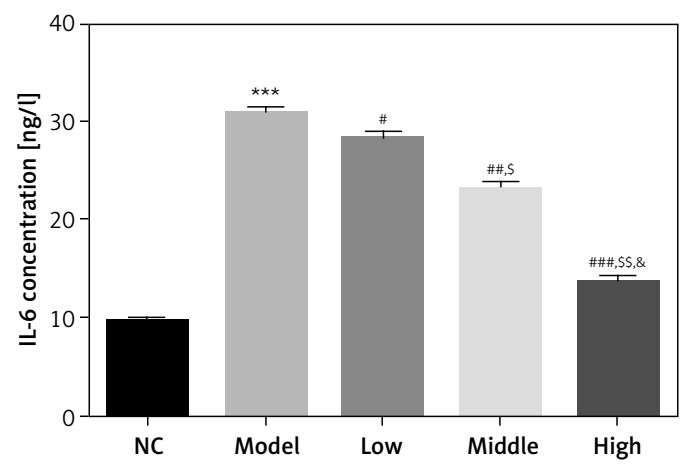

Figure 1. Cont. B - Apoptosis rate of different groups

NC - HUVECS treated with normal culture medium with normal glucose concentration, Model - HUVECS treated with high glucose, Low - HUVECS treated with high glucose and low-dose Vit. D, Middle - HUVECs treated with high glucose and middle-dose Vit. D, High - HUVECS treated with high glucose and high-dose Vit. $D$. ${ }^{* * *} P<$ 0.001 , compared with NC group; $" p<0.05$, $\# p<0.01$ $\# \# p<0.001$, compared with Model group; ${ }^{s} p<0.05$ ${ }^{s s} P<0.01$, compared with Low group; ${ }^{*} p<0.05$, compared with Middle group.

cantly reduced compared with the Model group (all $p<0.001$, Figure $5 \mathrm{~B}$ ); after transfection with the IncRNA MEG3 inhibitor sh-MEG3, the expression

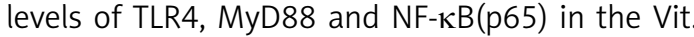
$D+$ sh-MEG3 group were significantly higher than those in the Vit. D group (all $p<0.001$, Figure $5 \mathrm{~B}$ ).

\section{Effect of IncRNA MEG3 knockout on the} amount of nuclear import of NF-kB(p65)

Compared with the NC group, the amount of nuclear import of NF- $\kappa \mathrm{B}(\mathrm{p} 65)$ in the Model group and shRNA-NC group was significantly increased (both $p<0.001$, Figure 6); compared with the Model group, the amount of nuclear import of NF- $\mathrm{kB}(\mathrm{p} 65)$ in the Vit. D group was significantly decreased after Vit. D intervention $(p<0.001$, Figure 6$)$; after transfection with the IncRNA MEG3 inhibitor sh-MEG3, the amount of nuclear import of NF$\kappa \mathrm{B}(\mathrm{p} 65)$ protein in the $\mathrm{Vit} . \mathrm{D}+$ sh-MEG3 group was increased significantly ( $p<0.001$, Figure 6).

\section{Discussion}

Many factors are involved in the complex pathogenesis of diabetic vasculopathy, among which the vascular endothelial cell injury caused by high glucose is the main initiator of the occurrence of vascular complications [17]. High glucose can not only cause apoptosis of vascular endothelial cells, but also activate the NF- $\kappa B$ pathway of endothelial cells, resulting in increased expression of TNF- $\alpha$, ICAM-1, MCP-1 and other inflammatory factors, 
A
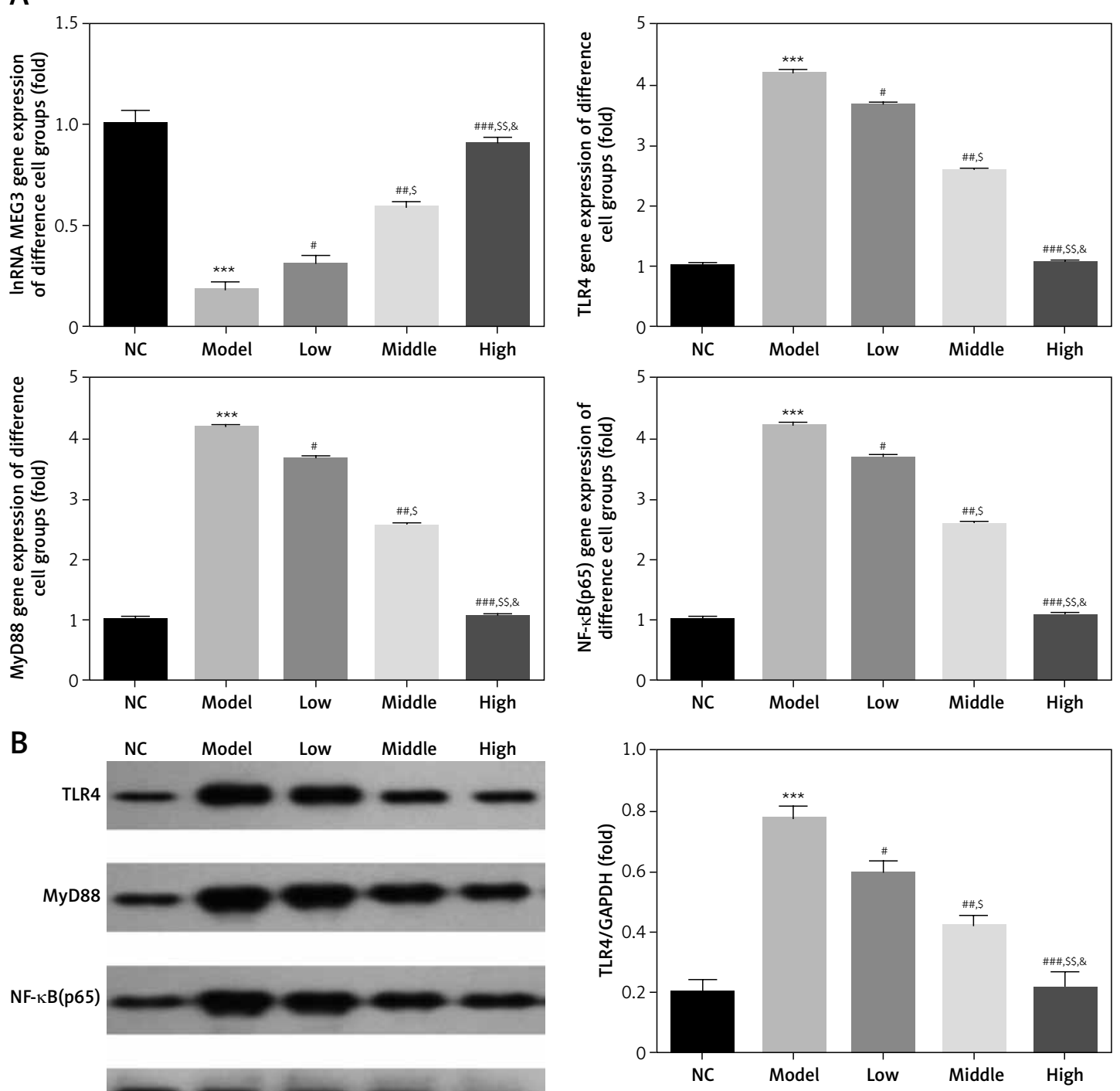

GAPDH
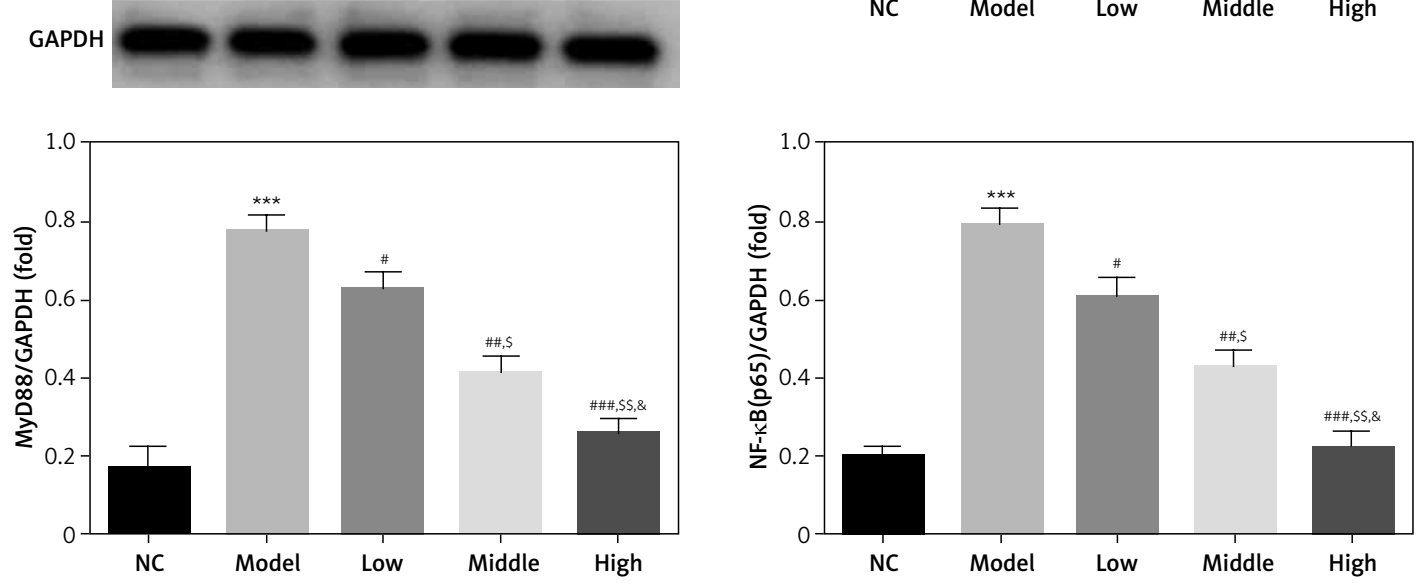

Figure 2. Effects of Vit. D on expression of related genes and proteins. A - Relative gene expression in different groups by RT-qPCR assay. B - Relative protein expressions by WB assay

NC - HUVECS treated with normal culture medium with normal glucose concentration, Model - HUVECS treated with high glucose, Low - HUVECS treated with high glucose and low-dose Vit. D, Middle-HUVECs treated with high glucose and Middledose Vit. D. High - HUVECS treated with high glucose and high-dose Vit. D. ${ }^{* * * P}<0.001$, compared with NC group; ${ }^{*} p<0.05$, ${ }_{\# \#} p<0.01$, \#\# $p<0.001$, compared with Model group; ${ }^{s} p<0.05,{ }^{s s} p<0.01$, compared with Low group; ${ }^{*} p<0.05$, compared with Middle group. 

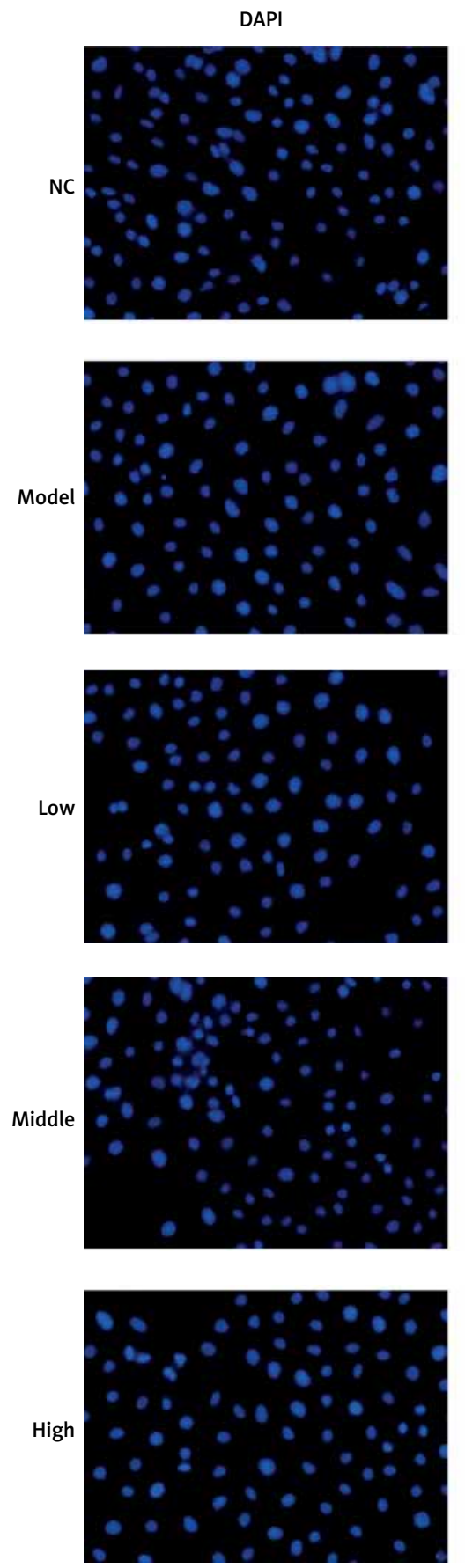

$\mathrm{NF}-\kappa \mathrm{B}(\mathrm{p} 65)$
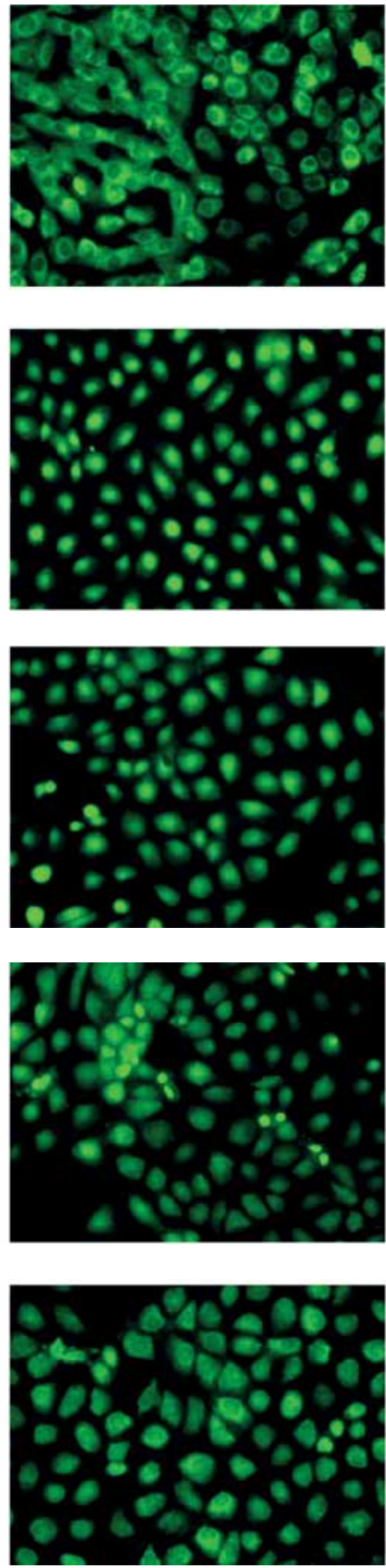

Merge
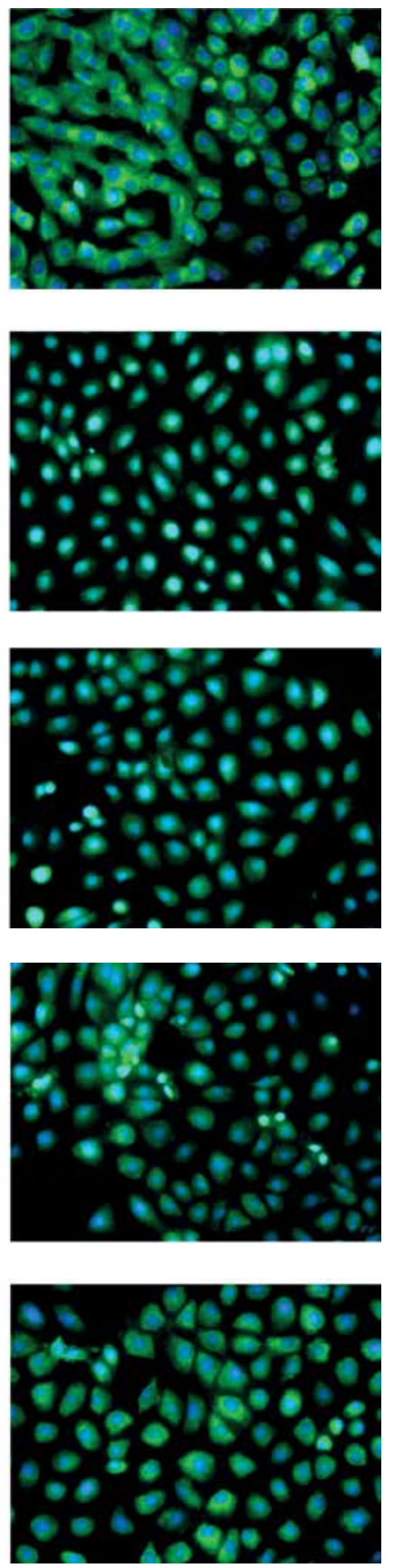

\section{B}

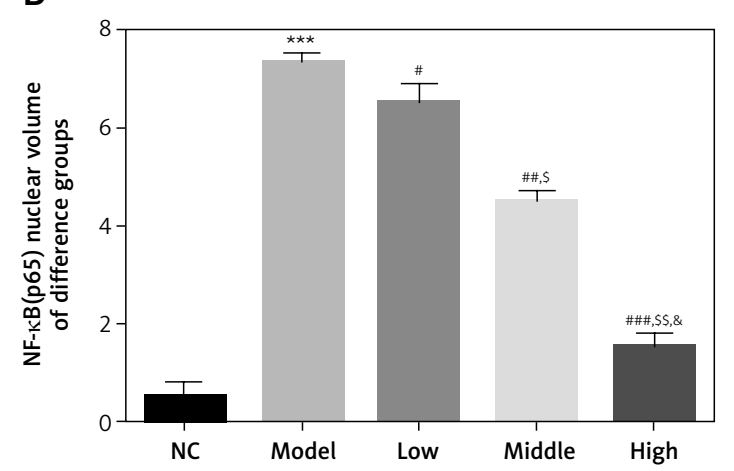

Figure 3. Effects of Vit. D on the nuclear import of $\mathrm{NF}-\kappa \mathrm{B}(\mathrm{p} 65)$

NC - HUVECS treated with normal culture medium with normal glucose concentration, Model - HUVECS treated with high glucose, Low - HUVECS treated with high glucose and low-dose Vit. D, Middle - HUVECS treated with high glucose and Middle-dose Vit. D, High - HUVECS treated with high glucose and high-dose Vit. $D .{ }^{* * *} P<$ 0.001 , compared with NC group; ${ }^{*} p<0.05$, ${ }^{\#} p<0.01$

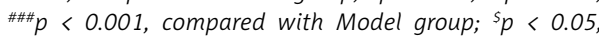
${ }^{s s} p<0.01$, compared with Low group; ${ }^{\&} p<0.05$, compared with Middle group. 
A
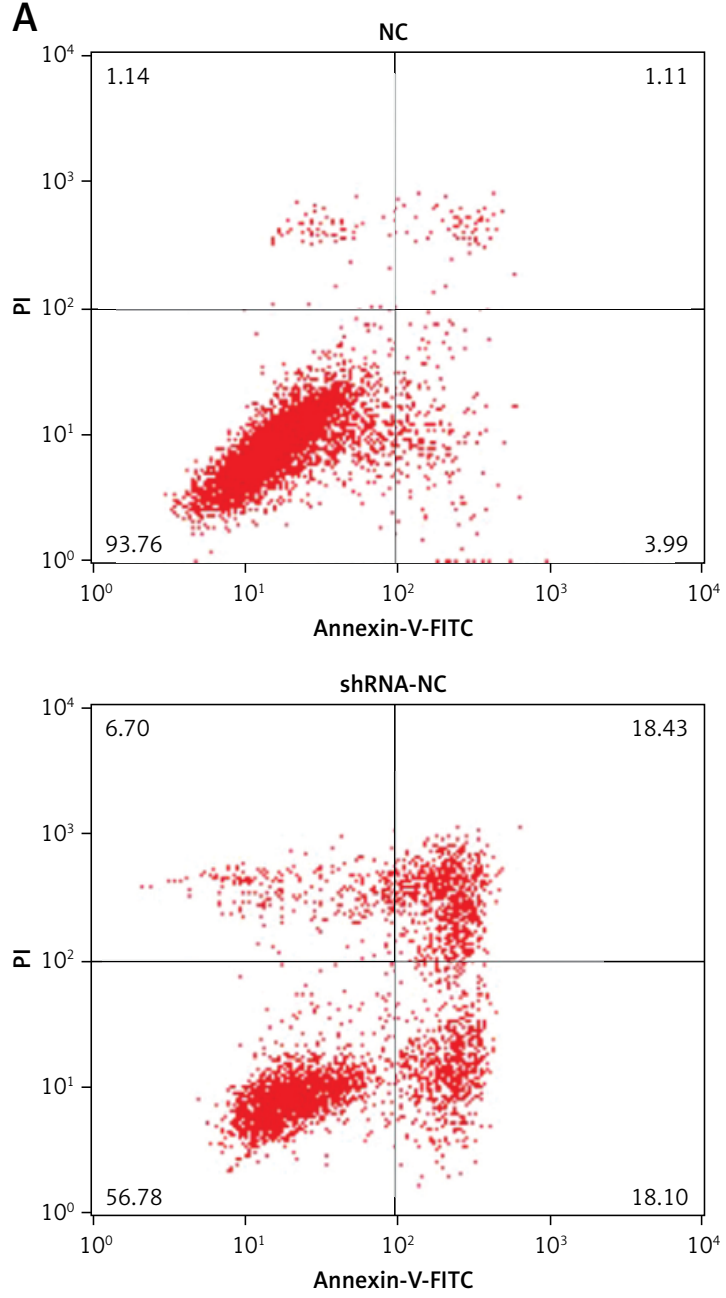

Vit. D + sh-MEG3

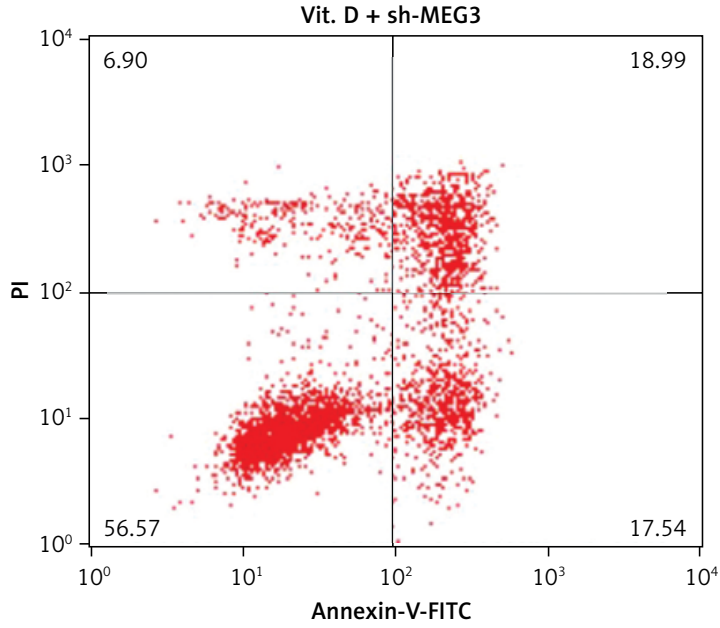

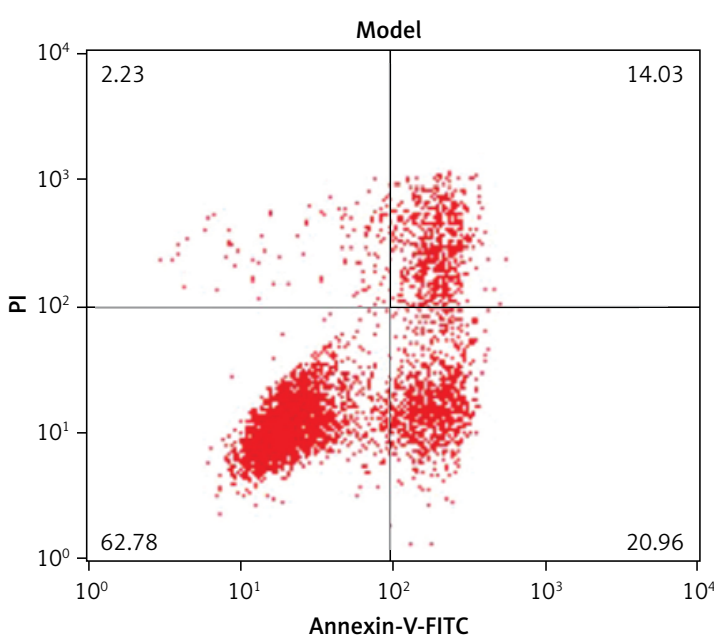
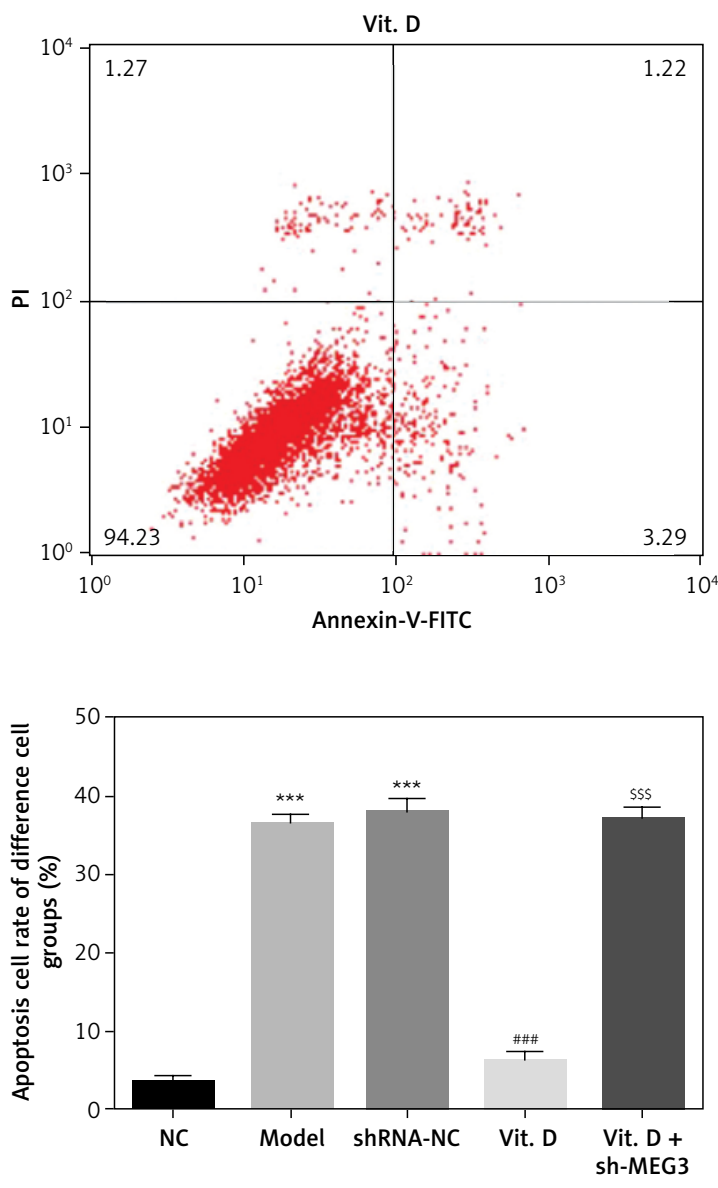

Figure 4. Role of IncRNA MEG3 in Vit. D improving the high glucose-induced vascular endothelial injury. A - Apoptosis rate of different groups

NC - HUVECS treated with normal culture medium with normal glucose concentration, Model - HUVECS treated with high glucose, shRNA-NC - HUVECS treated with high glucose and transfected with shRNA-NC, Vit. D-HUVECS treated with high glucose and treated with Vit. D, Vit. D + sh-MEG3 - HUVECs treated with high glucose and treated with sh-MEG3. ${ }^{* * *} P<0.001$, compared with NC group; ${ }^{\# \#} p<0.001$, compared with Model group; ${ }^{\$ S S} p<0.001$, compared with Vit. $D$ group. 
B
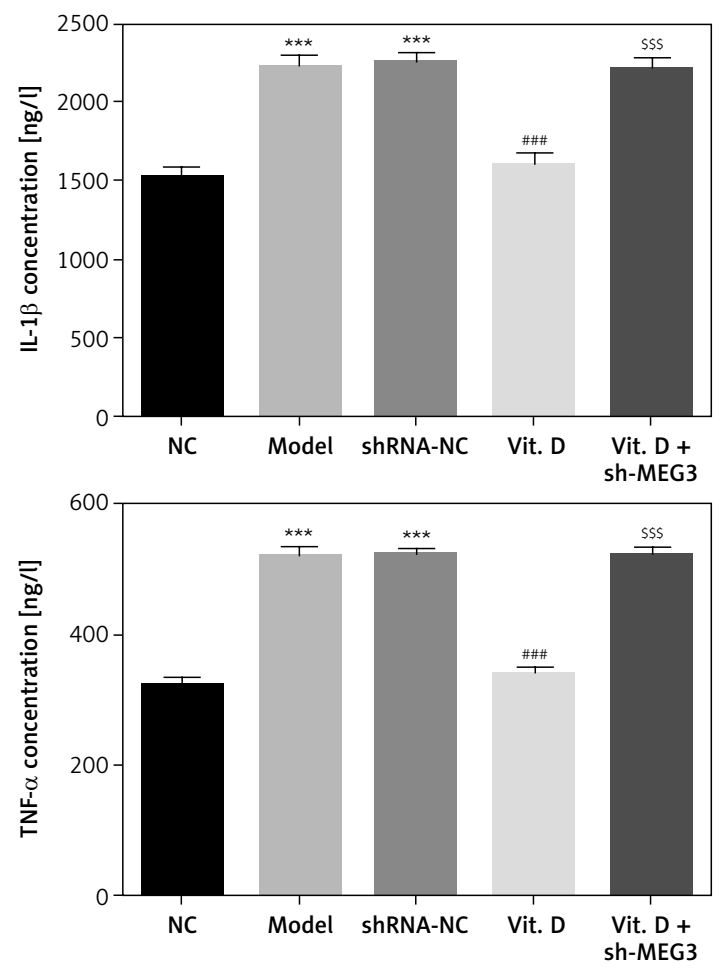

which will further aggravate the cell damage induced by high glucose [18]. Therefore, the most effective strategy to prevent and cure the occurrence of diabetic vascular complications theoretically is to control blood glucose level, but clinical studies have found that the problem of low glucose control efficiency is prevalent in diabetic patients [19]. While emphasizing the study of blood glucose control, it is of great practical significance for the control of diabetic vascular complications to actively explore the prevention and treatment measures for high glucose induced vascular endothelial cell injury. It was found in this research that the rise of inflammation factors and apoptosis caused by high glucose were significantly inhibited after Vit. D intervention, and there is a significant concentration-response relationship; in order to explore the specific action mechanism, relative mRNA expression levels were measured, and the results showed that IncRNA MEG3 was significantly increased, while depressing the TLR4/MyD88/NF-kB(p65) pathway.

Related research results have shown that IncRNAs have a key role in complications caused by diabetes [20-22]. LncRNA MEG3 is a newly discovered IncRNA, and some studies reported that IncRNA MEG3 has abnormal expression in a variety of diseases and plays an important role in the treatment of a variety of diseases [23-25]. Our present study found Vit. D had depressed high-glycemic-induced vascular endothelial cell apoptosis via increasing IncRNA MEG3. Therefore, it could be concluded that the improvement of high glucose-induced vascular endothelial injury by Vit. D

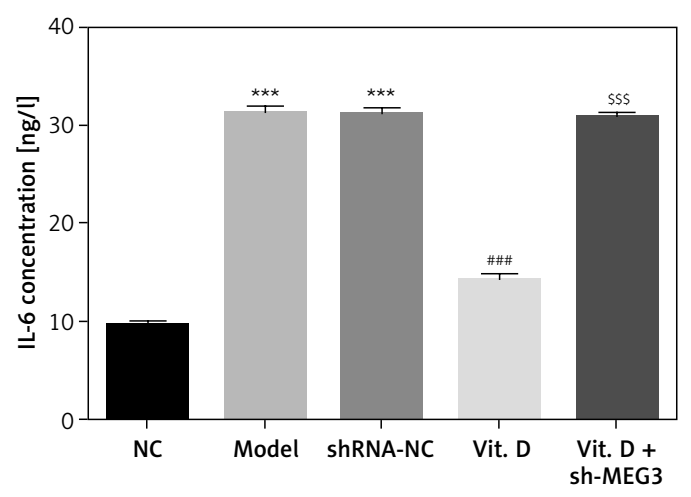

Figure 4. Cont. B - Inflammatory factors in different groups

NC - HUVECS treated with normal culture medium with normal glucose concentration, Model - HUVECS treated with high glucose, shRNA-NC - HUVECs treated with high glucose and transfected with ShRNA-NC, Vit. D-HUVECS treated with high glucose and treated with Vit. D, Vit. D "+ sh-MEG3 - HUVECS treated with high glucose and treated with sh-MEG3. ${ }^{* * *} P<0.001$, compared with NC group; ${ }^{\# \# p}<0.001$, compared with Model group; ${ }^{\text {ss }} p<$ 0.001 , compared with Vit. D group.

might be related to the increased expression of IncRNA MEG3. Meanwhile, studies have demonstrated that IncRNA MEG3 could effectively inhibit the anti-inflammatory effect of TLR4 pathway $[26,27]$. After the knockout of IncRNA MEG3, it was found that the apoptosis rate and TNF- $\alpha$, IL- 6 and IL-1 $\beta$ were significantly increased, and the improvement effect of Vit. D significantly disappeared; therefore, it could be concluded that Vit. D might play a role in diabetic vascular endothelial injury through IncRNA MEG3.

Induced by high glucose, the inflammatory signal of HUVEC cells was transmitted to the cells through TLR4 $[28,29]$, which stimulated a large amount of NF- $\mathrm{KB}(\mathrm{p} 65)$ transcription factors to be transferred into the nucleus, and led to the secretion of a large amount of TNF- $\alpha$, IL- 6 and IL- $1 \beta$ cytokines, thus initiating the inflammatory response $[30,31]$. The previous research just researched Vit. D's effects in inflammation improvement, however, the effects and relative mechanisms of Vit. D on diabetic vascular endothelial injury have been unclear. The results of this study demonstrated that, after Vit. D intervention, the amount of nuclear import of NF- $\mathrm{KB}(\mathrm{p} 65)$ was significantly inhibited with the inhibition of the TLR4/MyD88/ NF- $\mathrm{B}(\mathrm{p} 65)$ pathway; nevertheless, after the knockout of IncRNA MEG3, it was found that the improvement effect of Vit. $D$ on diabetic vascular endothelial injury disappeared, and the amount of nuclear import of NF- $\mathrm{KB}(\mathrm{p} 65)$ was significantly increased. Thus, it could be concluded that the role of Vit. D in the improvement of diabetic vascular 
A
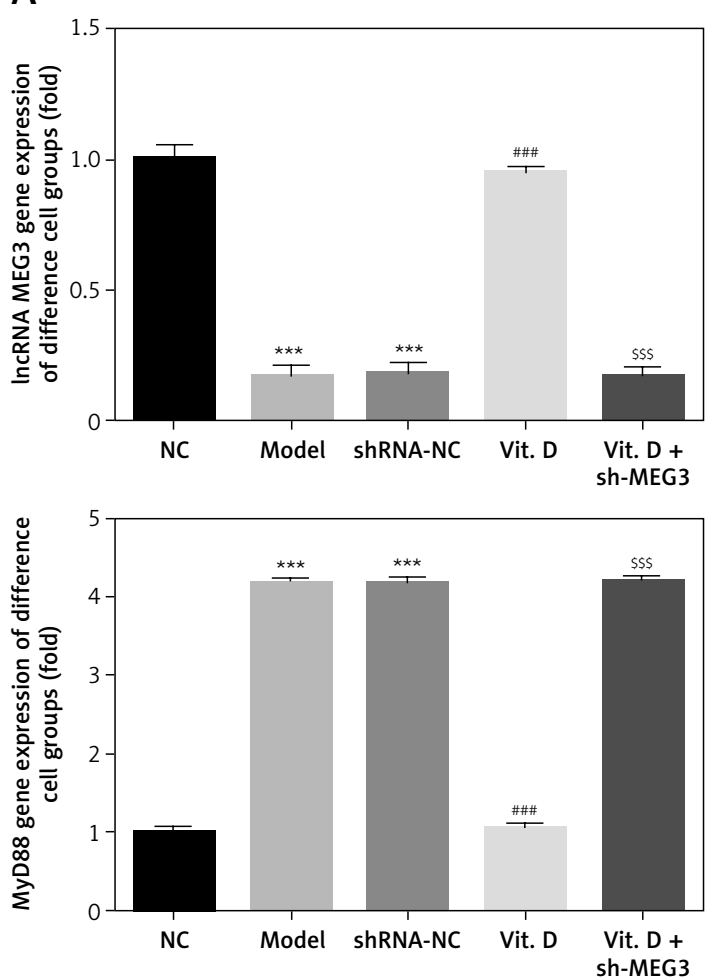

B NC Model shRNA-NC Vit. D $\begin{array}{r}\text { Vit. D + } \\ \text { sh-MEG3 }\end{array}$
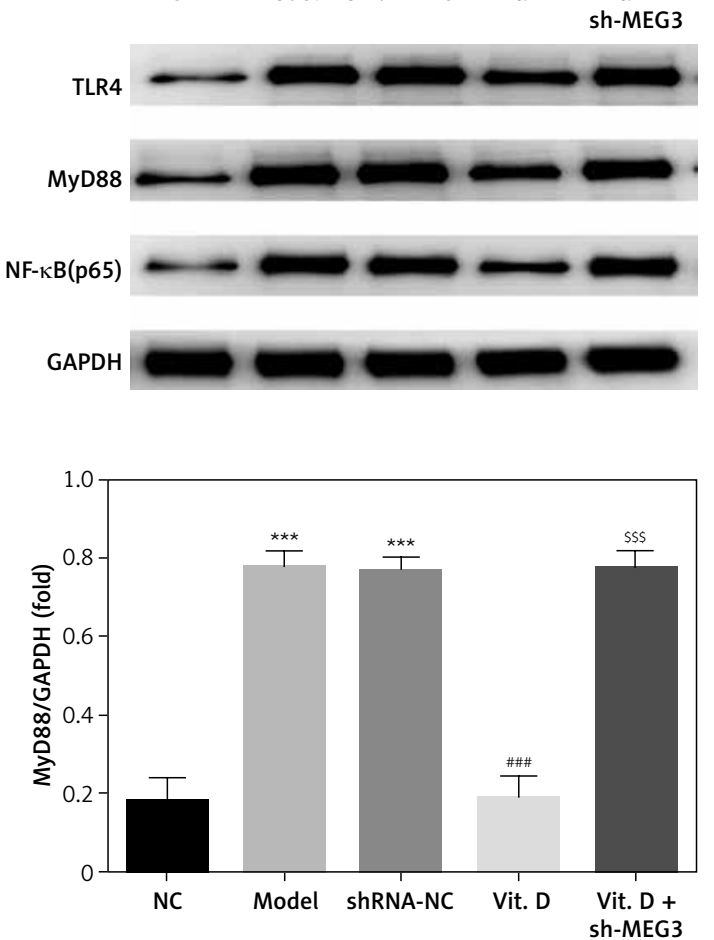
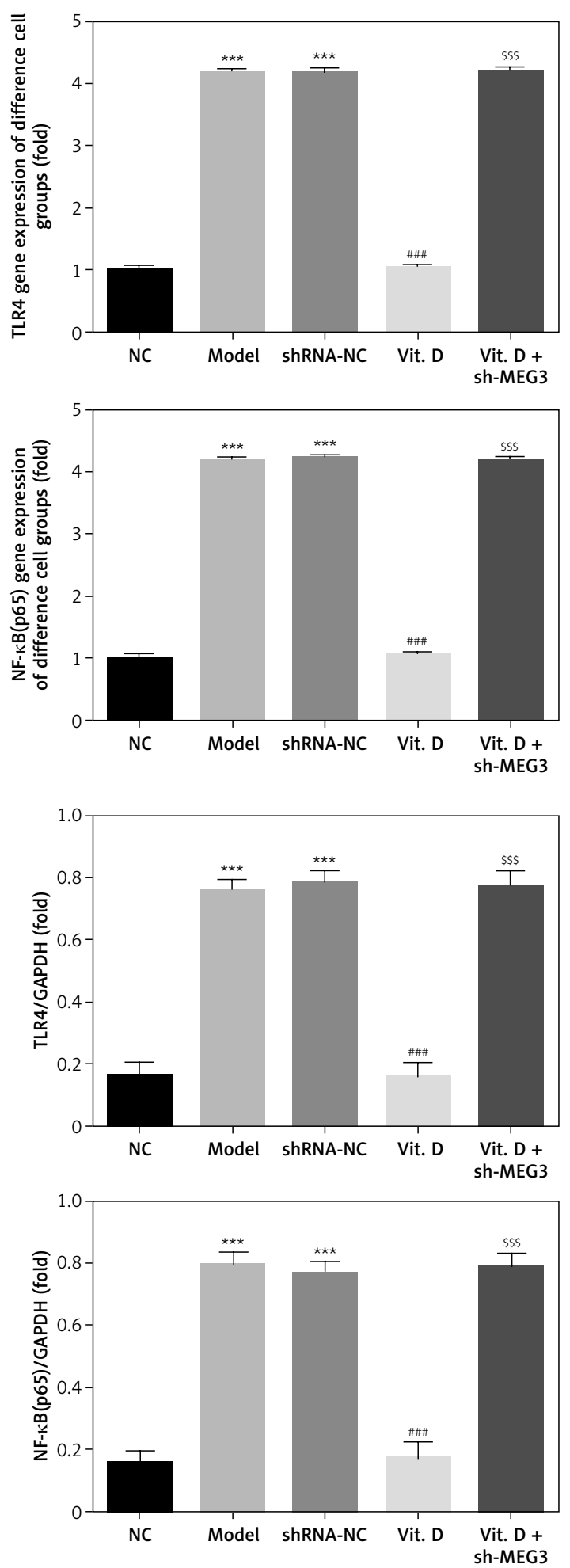

Figure 5. Effects of IncRNA MEG3 knockdown on expression of related genes (IncRNA MEG3, TLR4, MyD88 and $\mathrm{NF}-\mathrm{kB}(\mathrm{p} 65))$ and proteins (TLR4, MyD88 and NF- $\mathrm{kB}(\mathrm{p} 65))$. A - Relative gene expressions in different groups by RT-qPCR assay. B - Relative protein expression by WB assay

NC - HUVECS treated with normal culture medium with normal glucose concentration, Model - HUVECS treated with high glucose, shRNA-NC - HUVECS treated with high glucose and transfected with shRNA-NC, Vit. D-HUVECS treated with high glucose and treated with Vit. D, Vit. D + sh-MEG3 - HUVECs treated with high glucose and treated with sh-MEG3. ${ }^{* * *} P<0.001$, compared with NC group; ${ }^{\# \#} p<0.001$, compared with Model group; ${ }^{\$ S \$} p<0.001$, compared with Vit. D group. 

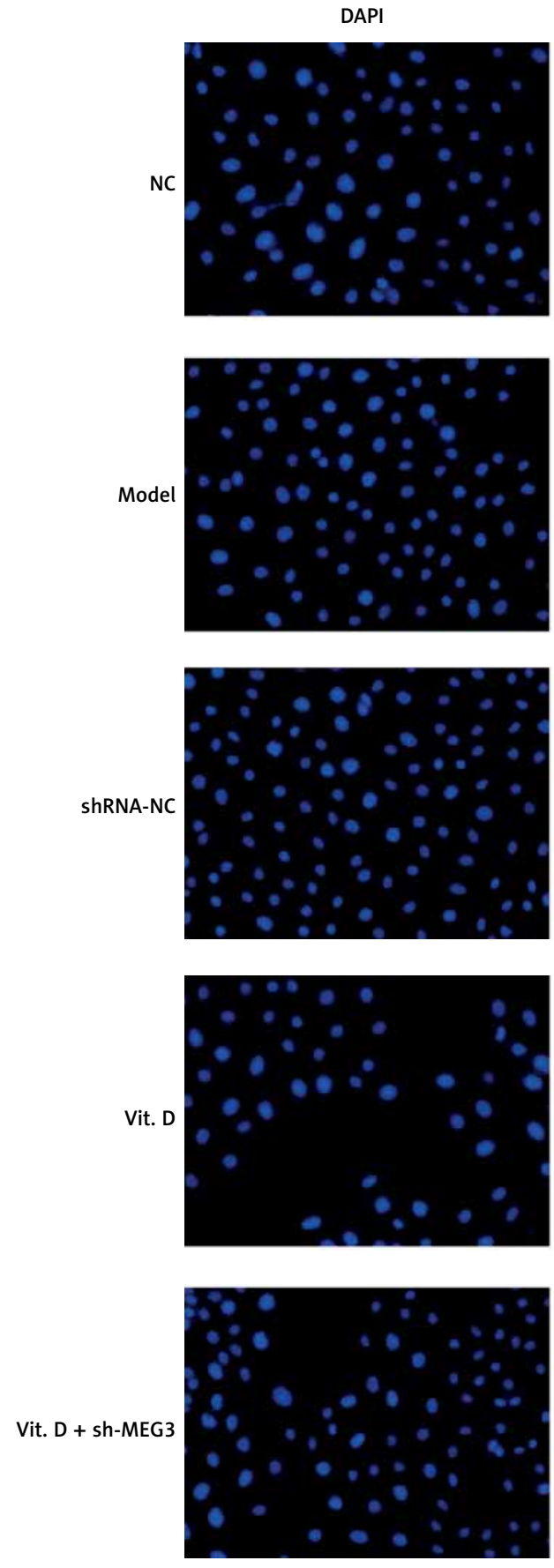
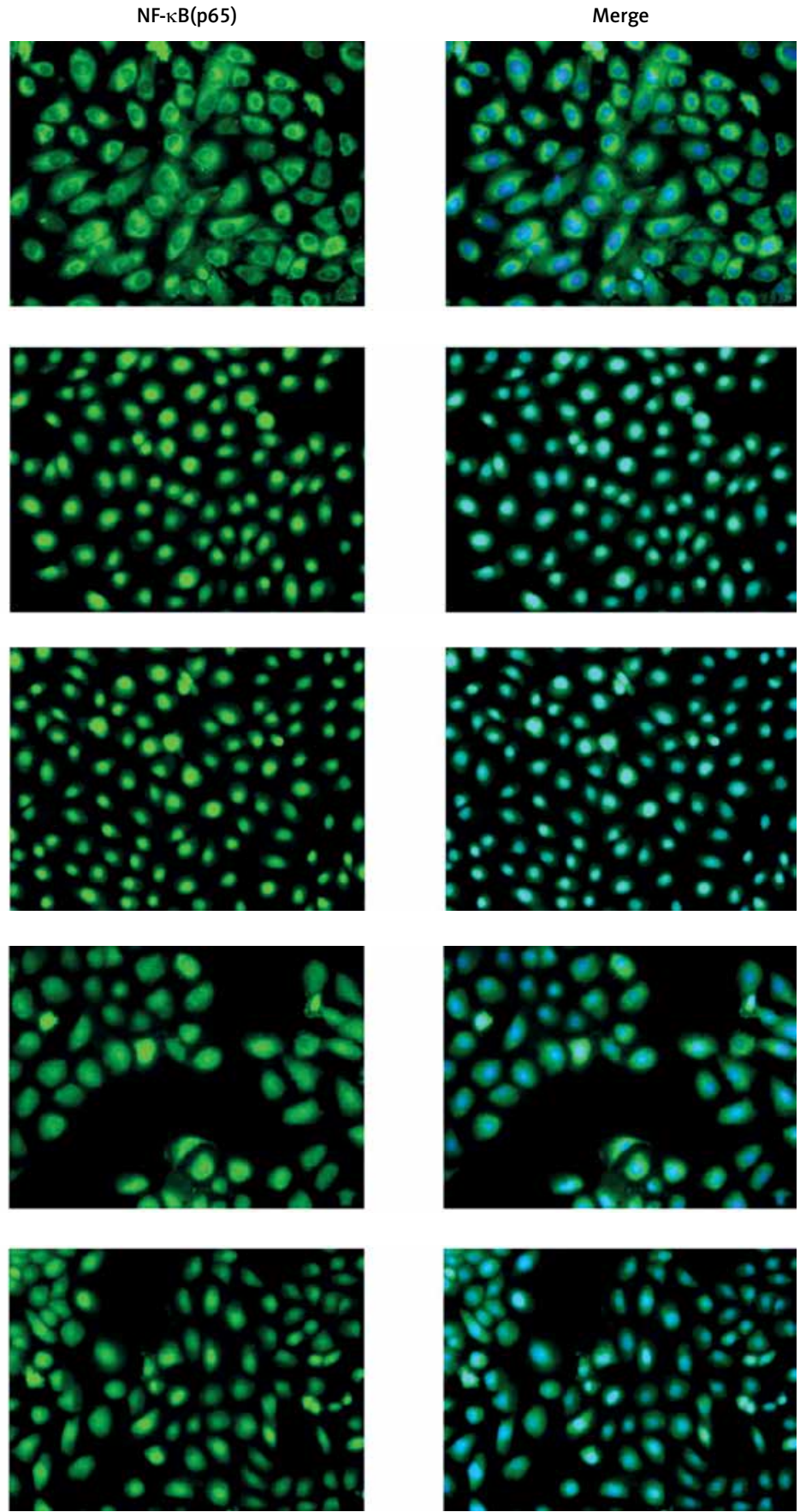

B

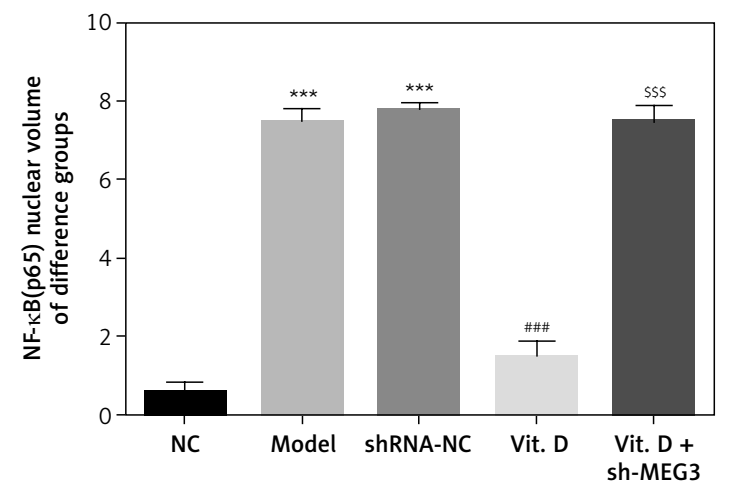

Figure 6. Effect of IncRNA MEG3 knockout on the amount of nuclear import of NF-KB (p65)

NC - HUVECS treated with normal culture medium with normal glucose concentration, Model - HUVECS treated with high glucose, shRNA-NC - HUVECs treated with high glucose and transfected with shRNA-NC, Vit. D - HUVECS treated with high glucose and treated with Vit. D, Vit. D + sh-MEG3 - HUVECS treated with high glucose and treated with sh-MEG3. ${ }^{* * *} P<0.001$, compared with NC group; \#\#\# < 0.001, compared with Model group; ${ }^{s s s} p<$ 0.001 , compared with Vit. $D$ group. 
endothelial injury might be achieved by the inhibition of the nuclear import of NF-kB(p65), which resulted from the negative regulation of the TLR4/ MyD88/NF-kB(p65) pathway by IncRNA MEG3.

\section{Acknowledgments}

Hua Wei and Qiongfang Zhang equal contribution to this study.

This study was supported by The First Batch of High-level Talent Scientific Research Projects of the Affiliated Hospital of Youjiang Medical University for Nationalities in 2019 (No. R20196314), Natural Science Foundation of Guangxi Province (No. 2019JJA140067), Natural Science Foundation of Guangxi Province (No. 2019JJB140036) and the Guangxi Natural Science Foundation (2019JJA140067).

\section{Conflict of interest}

The authors declare no conflict of interest.

\section{References}

1. Kayar Y, Agin M. The relationship between demographic and anthropometric characteristics and diabetic complications and number of hospitalizations in hospitalized diabetic patients. Arch Med Sci Civil Dis 2019; 4: e7-15.

2. Yu P, Guo J, Li J, Chen W, Zhao T. Co-expression network analysis revealing the key IncRNAs in diabetic foot ulcers. Arch Med Sci 2019; 15: 1123-32.

3. El Habashy S, Abd El Monem Adly A, Salah Eldin Mohamed Abdel Kader M, El-Tokhy Ali S. Predictors of future microalbuminuria in children and adolescents with type 1 diabetes mellitus in Egypt. Arch Med Sci Atheroscler Dis 2019; 4: e286-97.

4. Quillard T, Devallière J, Coupel S, Charreau B. Inflammation dysregulates Notch signaling in endothelial cells: implication of Notch2 and Notch4 to endothelial dysfunction. Biochem Pharmacol 2010; 80: 2032-41.

5. Stroka KM, Aranda-Espinoza H. Effects of morphology vs. cell-cell interactions on endothelial cell stiffness. Cell Mol Bioeng 2011; 4: 9-27.

6. Al-Rasheed NM, Al-Rasheed NM, Bassiouni YA, et al. Vitamin D attenuates pro-inflammatory TNF-alpha cytokine expression by inhibiting NF-kappaB/p53 signaling in hypertrophied rat heats. J Physiol Biochem 2015; 71 : 289-99.

7. El Agaty SM. Cardioprotective effect of vitamin D2 on isoproterenol-induced myocardial infarction in diabetic rats. Arch Physiol Biochem 2019; 125: 210-9.

8. Ponting CP, Oliver PL, Reik W. Evolution and functions of long noncoding-RNAs. Cell 2009; 136: 629-41.

9. Mercer TR, Dinger ME, Mattick JS. Long non-coding RNAs: insights into functions. Nat Rev Genet 2009; 10: 155-9.

10. Ponjavic J, Ponting CP, Lunter G. Functionality or transcriptional noise? Evidence for selection within long noncoding RNAs. Genome Res 2007; 17: 556-65.

11. Roth A, Diederichs S. Long noncoding RNAs in lung cancer. Curr Top Microbiol Immunol 2016; 394: 57-110.

12. Saito T, Kurashige J, Nambara S, et al. A long non-coding RNA activated by transforming growth factor-beta is an independent prognostic marker of gastric cancer. Ann Surg Oncol 2015; 22 Suppl 3: S915-22.
13. Wu GC, Pan HF, Leng RX, et al. Emerging role of long noncoding RNAs in autoimmune disease. Autoimmun Rev 2015; 14: 798-805.

14. Kameswaran V, Kaestner KH. The missing Inc(RNA) between the pancreatic beta-cell and diabetes. Front Genet 2014; 5: 200.

15. Wang Z, Ding L, Zhu J, et al. Long non-coding RNA MEG3 mediates high glucoseinduced endothelial cell dysfunction. Int J Clin Exp Pathol 2018; 11: 1088-100.

16. Zhang J, Guo Y, Ge W, Zhou X, Pan M. High glucose induces the apoptosis of HUVECs in mitochondria dependent manner by enhancing VDAC1 expression. Pharmazie 2018; 73: 725-8.

17. Ning RB, Zhu J, Chai DJ, et al. RXR agonists inhibit high glucose-induced upregulation of inflammation by suppressing activation of the NADPH oxidase-nuclear factor- $\mathrm{B}$ pathway in human endothelial cells. Genet $\mathrm{Mol}$ Res 2013; 12: 6692-707.

18. Sena CM, Pereira AM, Seiça R. Endothelial dysfunction a major mediator of diabetic vascular disease. Biochim Biophys Acta 2013; 1832: 2216-31.

19. Jiao XM, Zhang XG, XU XU, et al. Blood glucose fluctuation aggravates lower extremity vascular disease in type 2 diabetes. Eur Rev Med Pharmacol Sci 2014; 18: 2025-30.

20. Monnier P, Martinet C, Pontis J, Stancheva I, Ait-Si-Ali S, Dandolo L. H19IncRNA controls gene expression of the Imprinted Gene Network by receruiting MBD1. Proc Natl Acad Sci USA 2013; 110: 20693-8.

21. Pasmant E, Sabbagh A, Vidaud M, Bièche I. ANRIL, a long, noncoding RNA, is an unexpected major hotspot in GWAS. FASEB J 2011; 25: 444-8.

22. Liu S, Sheng L, Miao H, et al. SRA gene knockout protects against diet-induced obesity and improves glucose tolerance. J Biol Chem 2014; 289: 13000-9.

23. Zhou Y, Yang H, Xia W, et al. LncRNA MEG3 inhibits the progression of prostate cancer by facilitating $\mathrm{H} 3 \mathrm{~K} 27$ trimethylation of EN2 through binding to EZH2. J Biochem 2020; 167: 295-301.

24. Wu X, Li J, Ren Y, Zuo Z, Ni S, Cai J. MEG3 can affect the proliferation and migration of colorectal cancer cells through regulating miR-376/PRKD1 axis. Am J Transl Res 2019; 11: 5740-51.

25. Zhu J, Han S. Lidocaine inhibits cervical cancer cell proliferation and induces cell apoptosis by modulating the IncRNA-MEG3/miR-421/BTG1 pathway. Am J Transl Res 2019; 11: 5404-16.

26. Li R, Fang L, Pu Q, et al. MEG3-4 is a miRNA decoy that regulates IL-1beta abundance to initiate and then limit inflammation to prevent sepsis during lung infection. Sci Signal 2018; 11: eaao2387.

27. Tao XW, Zeng LK, Wang HZ, Liu HC. LnCRNA MEG3 ameliorates respiratory syncytial virus infection by suppressing TLR4 signaling. Mol Med Rep 2018; 17: 4138-44.

28. Mahmoudi J, Sabermarouf B, Baradaran B, Sadat-Hatamnezhad L, Shotorbani SS. Up-regulation of TLR2 and TLR4 in high mobility group Box1-stimulated macrophages in pulpitis patients. Iran J Basic Med Sci 2017; 20: 209-15.

29. Li JG, Lin JJ, Wang ZL, et al. Melatonin attenuates inflammation of acute pulpitis subjected to dental pulp injury. Am J Transl Res 2015; 7: 66-78.

30. Song F, Sun H, Wang Y, et al. Pannexin3 inhibits TNFalpha-induced inflammatory response by suppressing NF-kappaB signalling pathway in human dental pulp cells. J Cell Mol Med 2017; 21: 444-55.

31. Wu H, He M, Yang R, Zuo Y, Bian Z. Astrocyte elevated gene-1 participates in the production of pro-inflammatory cytokines in dental pulp cells via NF-kappaB signaling pathway. Int Endod J 2018; 51: 1130-8. 